\title{
HIBRIDISMO: um tropo enganoso e a história do uso de uma metáfora.
}

\section{HYBRIDISME: \\ une expression trompeuse et l'histoire de l'utilisation d'une métaphore.}

\author{
HYBRIDISM: \\ a deceptive trope and the story of using a metaphor.
}

\section{Resumo}

O presente artigo é fruto de uma comunicação oral realizada em dois eventos distintos, quando foram motivadoras de ricas discussões. Apresenta-se como um ensaio bibliográfico e histórico com o objetivo de refletir sobre a adequação da metáfora hibridismo e híbrido na caracterização de fenômenos culturais importantes, como é o caso do processo histórico de encontros de culturas, comumente tratados como mestiçagens culturais. Questiona a adequação da metáfora, tendo como fundamento o estudo histórico dessa nomeação, por parte de historiadores e de outros cientistas sociais ao longo da história, centrando-se na observação contemporânea desse uso, principalmente no âmbito da América latina. O texto busca apresentar a preocupação com respeito ao uso cultural das metáforas exemplificando com o caráter dúbio e múltiplo dos significados da palavra híbrido, construído no decorrer da história e seu uso para adjetivar as riquezas culturais. Tal preocupação busca ter dimensão conceitual e metodológica e, neste sentido, perscruta as temporalidades do conceito de hibridismo biológico e em que medida a palavra híbrido está presente no pensamento moderno e não moderno. Apresenta questões sobre os contornos semânticos assumidos pela palavra em contextos histórico-culturais distintos e, ao final, questiona a tradição (entendendo-a como transmissão) de seu uso, muitas vezes irrefletido, naturalizado. Conclui que as expressões híbrido(a)/hibridismo, por sua dubiedade interpretativa, são pouco aderidas às realidades interpretadas e, assim, servem pouco como convenções para o entendimento denotativo de nossas interpretações.

Palavras-Chaves: Híbrido- Hibridismo- Cultura- Transculturação- mestiçagens.

\begin{abstract}
This article is the result of an oral communication held in two different events, when they were motivators of rich discussions. It is presented as a bibliographic and historical essay with the objective of reflecting on the adequacy of the hybridism and hybrid metaphor in the characterization of important cultural phenomena, as is the case of the historical process of meeting cultures, commonly treated as cultural miscegenations. It questions the adequacy of the metaphor, based on the historical study of this nomination, by historians and other social scientists throughout history, focusing on the contemporary observation of this use, mainly in the context of Latin America. The text seeks to present the concern with respect to the cultural use of metaphors, exemplifying with the dubious and multiple character of the meanings of the word hybrid, built throughout
\end{abstract}

\footnotetext{
${ }^{1}$ Professor associado do departamento de História da Universidade Federal de Minas Gerais.

E-mail: jnmeneses@gmail.com
} 


\section{Hibridismo: \\ Um tropo enganoso e a história do uso de uma metáfora}

José Newton Coelho MENESES

history and its use to adjectify cultural riches. This concern seeks to have a conceptual and methodological dimension and, in this sense, examines the temporalities of the concept of biological hybridism and the extent to which the word hybrid is present in modern and non-modern thought. It presents questions about the semantic contours assumed by the word in different historical-cultural contexts and, at the end, questions the tradition (understanding it as transmission) of its use, often thoughtless, naturalized. It concludes that the expressions hybrid (a) / hybridism, due to their interpretive dubiousness, are little adhered to the interpreted realities and, thus, serve little as conventions for the understanding of our interpretations.

Keywords: Hybrid- Hybridism- Culture- Transculturation- crossbreeding.

\section{Resumé}

Le présent article est le fruit d'une communication orale qui a eu lieu lors de deux événements distincts, sources de riches discussions. Il est présenté comme un essai bibliographique et historique visant à réfléchir sur l'adéquation de la métaphore hybridisme et hybride dans la caractérisation de phénomènes culturels importants, comme le processus historique de rencontres de cultures, généralement traités comme des métissages culturels. Il remet en question l'adéquation de la métaphore sur la base de l'étude historique de cette dénomination par des historiens et d'autres scientifiques sociaux tout au long de l'histoire, en se concentrant sur l'observation contemporaine de cet usage, principalement dans le cadre de l'Amérique latine. Le texte cherche à présenter une préoccupation concernant l'usage culturel des métaphores en illustrant le caractère ambigu et multiple des significations du mot hybride, construit au cours de l'histoire et son utilisation qualifier les richesses culturelles. Cette préoccupation cherche à avoir une dimension conceptuelle et méthodologique et, en ce sens, examine les temporalités du concept d'hybridisme biologique et dans quelle mesure le mot hybride est présent dans la pensée moderne et non moderne. Nous poserons des questions sur les contours sémantiques assumés par la parole dans des contextes historiques et culturels différents et, pour finir, remettrons en cause la tradition (en la comprenant comme transmission) de son usage, souvent irréfléchi, devenu naturel. Nous conclurons en disant que les expressions hybride/hybridisme, en raison de leur double interprétation, sont peu représentatives des réalités interprétées et, pour cette raison, servent donc peu de conventions pour la compréhension de nos interprétations.

Mots clés: hybride - hybridisme - culture - transculturation - métissages.

Todas as culturas estão envolvidas entre si, nenhuma delas é única e pura, todas são híbridas, heterogêneas. Edward W. Said

A expressão de sentidos claros e sem ambiguidades, como uma busca da linguagem da ciência, é consentimento construído na história da modernidade. As palavras, na convenção instituída para que a ciência tenha uma linguagem universal, devem ter leitura denotativa do objeto interpretado. Na história das culturas, o termo hibridismo vem sendo usado como metáfora que pretenderia deixar claras e não ambíguas as características forjadas por encontros de culturas distintas que dão origem a novos repertórios culturais, a estruturas sociohistóricas sui generis e complexas e, em consequência, ricas, capazes de uma reprodução de vivências sociais identitárias de grupos, de sociedades, de culturas. Este texto quer refletir sobre a adequação 
dessa metáfora à caracterização que se busca dar a fenômenos culturais importantes, como é o caso do processo histórico de mestiçagens culturais. Neste sentido, reflete sobre tal adequação, tendo como fundamento o estudo histórico dessa nomeação, por parte dos historiadores e de outros cientistas sociais, no âmbito da América latina. ${ }^{2}$

Como metáfora - relação de semelhança subentendida entre o sentido próprio e o figurado -, híbrido e hibridismo são, assim, translações de significação do sentido que têm na História Natural e na Biologia, para o sentido figurado que se quer dar a processos sócio-históricos. É uma escolha representativa para dar significado a um produto cultural que queremos adjetivar.

A preocupação aqui apresentada é, ao mesmo, tempo, manifestada no respeito ao uso cultural das metáforas, mas, por outro lado, no caráter dúbio e múltiplo dos significados da palavra híbrido, construído no decorrer da história. Os processos de encontros culturais, objetos fundamentais na tradição de reflexões sobre as culturas, são expressos metaforicamente por essa expressão que adquire nessa multiplicidade de sentidos, caráter dúbio, não denotativo, o que contraria uma regra básica da linguagem científica. A preocupação de nossas reflexões, portanto, tem dimensão conceitual e metodológica. Propõe perscrutar quando o conceito de hibridismo biológico surge na história; em que medida a palavra híbrido está presente no pensamento moderno e não moderno e, enfim, quais os contornos semânticos assumidos pela palavra em contextos histórico-culturais distintos. Nessa busca, problematizamos (pouco respondemos questões) as várias terminologias que, em História, traduzem o sentido buscado para designar as fronteiras culturais ou a dificuldade em delimitá-las, em uma ideia de continuum cultural. Neste sentido, procuramos aquilatar a força da expressão mestiçagem nas línguas latinas (métissage, em francês; mestizaje, em espanhol e metticcia, em italiano) e a falta de terminologia sinônima no inglês, onde o uso de hibridization pode pressupor a força da expressão hibridismo, a partir da tradução do inglês e da hegemonia da língua inglesa no espaço histórico ocidental.

É bom, de antemão, salientar o costume em nós de naturalizarmos as nossas representações. Representamos uma certa característica cultural e a convencionamos como algo natural. É o caso da expressão hibridismo/híbrido/híbrida. Classificamos como híbrida uma cultura ou uma expressão da cultura, pela ideia de que ela é, em sua formação, a junção de características distintas. Em certo consenso, essa construção cultural torna-se natural e não pensamos mais na questão.

\footnotetext{
2 Este texto deriva de uma comunicação oral apresentada em dois momentos distintos, quando gerou discussões acirradas: Primer Taller sobre un Proyecto de Diccionario Histórico - Mestizajes en los Mundos Ibéricos, em Sevilla, Espanha e XXIX International Congress of the Latin American Studies Association, em Toronto, Canadá, dois eventos ocorridos em 2010. Nesses 10 anos ficou "esquecido" (melhor dizer abandonado), a não ser em um ou outro momento, em sala de aula, quando foi usado provocativamente, sempre suscitando iguais acirramentos reflexivos. É por esse motivo provocativo e pelo estímulo de Sidiana Ferreira de Macêdo que ele vem a público.
} 


\section{Hibridismo: \\ Um tropo enganoso e a história do uso de uma metáfora}

José Newton Coelho MENESES

Comecemos, então por definir uma metáfora: é um tropo (emprego de palavra em sentido figurado) que consiste na transferência de uma palavra para um âmbito semântico que não é o do objeto que ela designa, e que se fundamenta numa relação de semelhança subentendida entre o sentido próprio e o figurado. ${ }^{3}$ A semântica, esclareçamos, é o estudo das mudanças ou translações sofridas, no tempo e no espaço, pela significação das palavras (com especificidades, esse, também, é o objeto da semiótica). As metáforas, portanto, tentam denotar um sentido claro para a linguagem explicativa, mas podem se mostrar enganosas. Como quer Peter Burke, "todos os termos, metafóricos ou não, precisam ser manuseados com cuidado e (...) é mais fácil fazer isso se virmos a linguagem da análise como sendo ela mesma parte da história da cultura." ${ }^{4}$ Os termos híbrido(a), hibridismo têm, ao longo da história, como veremos, significados não usados apenas para o campo da História natural e da Biologia, mas na designação de outros processos, inclusive socioculturais.

\section{VALORES E ANORMALIDADES.}

Híbrido é adjetivo originado do grego Hybris, hybridos e da expressão latina Hybridus, através do francês Hybride, com sentido de mistura, de misto. Na mitologia grega Hybris é a falta de medida ou a desmedida que leva ao descontrole. De modo geral, na simbologia mitológica de diversas culturas ocidentais, os híbridos têm sentido e valores que mostram deformidade, caráter disforme, monstruoso (mesmo que, às vezes, expressão do sagrado). Assim, sereias, esfinges, centauros e outros seres, misturas animalizadas ou humanizadas, mas com partes de ambos, simbolizam valores, mas denotam anormalidades. ${ }^{5}$

Nas ciências biológicas, hibridação é, principalmente após Mendel, o cruzamento de dois indivíduos de raças ou, mais raramente, de espécies diferentes. ${ }^{6}$ Há, também, a hibridação celular, processo experimental que permite a multiplicação de dois núcleos celulares (provenientes de animais ou vegetais diferentes) no interior da mesma célula. Nessa área da ciência, existem especificidades, conforme o objeto da investigação ou o objetivo do produto que se quer obter. Em Zootecnia, é o método de reprodução natural ou induzido, que consiste na união de parceiros geneticamente afins, porém especificamente distintos. A hibridação mais comum é a que se verifica entre as espécies cavalar e asinina, originando um produto com vigor físico, porém infértil (o burro). Entre animais domésticos e selvagens são citadas as hibridações entre cavalo e zebra, boi e bisão, cão e lobo.

\footnotetext{
${ }^{3}$ Definição com base em alguns dicionários da língua portuguesa, sobretudo FERREIRA (1988) e HOUAISS (2003).

${ }^{4}$ BURKE (2003, P. 40).

${ }^{5}$ CHEVALIER \& GHEERBRANT (2006, P. 491).

${ }^{6}$ Johann Mendel, botânico morávio (1822-1884) que, a partir de experiências com ervilhas lisas e rugosas (1856 a 1864) propõe a Lei da segregação genética e a Lei da segregação independente, além do processo de transmissão de caracteres, bases para os estudos genéticos, a partir de então.
} 
$\mathrm{Na}$ Botânica, a hibridação é realizável entre diferentes vegetais da mesma espécie e do mesmo gênero. É graças à hibridação que se pode multiplicar a variedade de flores e de frutos cultivados. Na maioria das vezes, o híbrido resultante do processo, além de maior longevidade, tem crescimento mais rápido e mais vigoroso que o dos "pais" devido aos resultados da heterose. ${ }^{7}$ No caso animal, alguns híbridos interespecíficos são fecundos; outros são estéreis. A despeito da busca produtiva nos vegetais e nos animais, o processo de hibridação, o hibridismo (ou a hibridez) é, nessas áreas da ciência, visto como uma irregularidade, uma anomalia, uma adulteração de caracteres genuínos. Usa-se com certo cuidado, observando-se bem os resultados e sua durabilidade e conveniência.

A utilização da expressão também acontece em gramática quando se quer explicar a formação de palavras com elementos ou radicais de línguas diferentes. Exemplo de hibridismo gramatical é monóculo, do grego monos (um), associado ao latim oculus (olho).

É de uso corrente, ainda, em Geologia, para designar a mistura entre dois magmas ou a contaminação de um magma pela sua rocha encaixante. A linguagem da Geologia, também expressa esses fenômenos como assimilação. Em Química há a Hibridação dos orbitais, que é a substituição de um certo número de orbitais atômicos de um mesmo átomo por um mesmo número de orbitais (chamados híbridos), obtidos de combinações de orbitais iniciais.

$\mathrm{Na}$ área da agricultura, o hibridismo tem significado de vigor físico, quando se reconhece que o animal híbrido ou a planta híbrida, mesmo que às vezes incapazes de se reproduzir, tem força física e resistência às condições sanitárias e ambientais que favorecem o seu uso e a sua produção. No entanto, pode ter, também, o significado de degenerescência, quando os sucessivos cruzamentos (de vegetais ou de animais) deixam de alcançar os objetivos pressupostos.

Em Zootecnia e na Veterinária são comuns e corriqueiras as expressões meio sangue, 1/4 de sangue, ${ }^{1 / 8}$ de sangue, etc. para representar a porcentagem de sangue europeu e mestiço nos cruzamentos bovinos. ${ }^{8}$ Nessa prática de reprodução animal, vários cruzamentos vão sendo construídos, de acordo com as necessidades produtivas e as condições ambientais e pode-se chegar ao puro por cruza, quando os sucessivos cruzamentos de animais mestiços com um animal de mesma raça levam às características daquela raça pura. Não vamos aqui entrar na seara racial para não fugirmos ao tema. É, no entanto, factível a constatação de que algumas referências intelectuais de tempos não tão distantes de nós, trazem a ideia de culturas híbridas que vão se "aperfeiçoando" pela mistura sequencial com uma cultura original (ou pura) até dela se aproximar. ${ }^{9}$

\footnotetext{
${ }^{7}$ Heterose é a união de gens distintos no processo reprodutivo, visando produtos com características específicas.

${ }^{8}$ Interessante que em francês, a expressão sang mêlé é usada popularmente para designar "meio sangue" racial, mas também, mistura, embaralhamento, confusão.

9 As "políticas de branqueamento" preconizadas no século XIX e início do XX são exemplos dessas tentativas de discursos teóricos. Ver, especialmente, DIWAN (2007).
} 


\section{Hibridismo: \\ Um tropo enganoso e a história do uso de uma metáfora}

José Newton Coelho MENESES

Nos dicionários contemporâneos da língua portuguesa, em suma, hibridação, hibridar, hibridez, hibridismo e híbrido, especificam sentidos que perpassam várias áreas do conhecimento e que traduzem, geralmente, cruzamentos entre variedades, misturas entre espécies, misturas de componentes diferentes, ${ }^{10}$ irregularidade, anomalia, adulteração de caracteres genuínos e mescla.

O Vocabulário Portuguez e Latino, de Raphael Bluteau, editado em vários volumes, em Lisboa, entre 1712 e 1721 e completado com mais cinco mil verbetes pelo mesmo autor em 1728, não traz o verbete Híbrido ou Hibridismo, mas discute seu uso, desde Plínio, no verbete Mestiço. Vejamos o verbete:

Mestiço. Diz-se dos animaes racionaes, \& irracionaes. Animal mestiço. Nascido de pay, \& may de differentes espécies, como um, leopardo, \&c. Misti generis animans antis omn. Gen. Hibrido, ou como quer Scaligero, \& Vossio, que se escreva Ibrido, o. Masc. (\& não Hybris), quer dizer, Nascido de hum porco montez, \& hua porca domestica. Assim no lo ensina Plinio no cap. 53 do livro 8, logo no principio, donde explica a palavra Hibrido pelo adjectivo Semiferus, acrescentando que tem dito dos homens, nascidos de pays de differentes naçoens. Eis aqui as palavras de Plinio. In nullo genere (falla nos porcos montezes) a què facilis mixtura cum fero, qualiter natos antigui Hybridas Vocaban, céu semíferos: ad homines quaque, ut $m$ C. Antoniun, Ciceronisin Confulatu Collegan, appelatione translata. Homem mestiço. Nascido de pays de differentes nações, v. g. Filho de Portuguez, \& de India, ou de pay Indio, e de may Portugueza, Ibrido, ou Hybrido, a. Masc. No Plural se poderá dizer Bigeneri, a. a. que se acha em Varro. Mas no singular não quizera eu dizer Bigenus, eris, nem Bigeneris, ou Bigenere, palavras q no seu thesouro da língua Latina, Roberto Estevão tem posto sem exemplo. ${ }^{11}$

Como vemos, no início do século XVIII, Raphael Bluteau, tentando definir o termo mestiço, considera a possibilidade de seu uso tanto para animais quanto para a espécie humana, observando as distinções genéricas, mas, ainda, as culturais, uma vez que homens de nações diferentes (culturas distintas) geram, ao se reproduzirem, homens mestiços. Híbrido ou Íbrido é designação atribuída por ele a Plínio, para designar a mesma situação que ele quer definir como mestiço, ou seja, produtos humanos. O verbete Mestiço de Bluteau, então, considera as palavras mestiço e híbrido como sinônimas, ou, pelo menos, como processos similares de mesclas reprodutivas entre animais de espécies diferentes e entre homens de culturas ou "nações" distintas. Como explicita bem em seu verbete, antes de definir animal mestiço e homem mestiço, "diz-se dos animais racionais e irracionais". 12

\footnotetext{
${ }^{10}$ No caso da informática há o computador híbrido com tecnologias analógicas e digitais convivendo no mesmo aparelho.

${ }^{11}$ BLUTEAU (1712).

${ }_{12}$ Pesquisado, ainda, o Diccionario da lingua portugueza - recopilado dos vocabularios impressos ate agora, e nesta segunda edição novamente emendado e muito acrescentado, por Antonio de Moraes Silva. (SILVA: 1813), onde não constam os vocábulos "híbrido", "Ibrido"ou "mestiço" e"mestiçagem", além de estudos sobre os dicionários antigos da língua portuguesa, como descrito a seguir: NUNES (Sem data); MURAKWA (2006); MURAKAWA (1997); PETTER \& NUNES (2002); SILVESTRE (2009); VERDELHO (Sem data); VERDELHO (2003).
} 
O uso da palavra híbrido, como nos demonstra Raphael Bluteau, já é usual na antiguidade. O naturalista romano Plínio, o velho (Caius Plinius Secundus - 23-79), no ano de 77 escreveu "Naturalis Historia", um vasto compêndio das ciências antigas, em trinta e sete volumes, base essencial para a literatura utilitária e para os dicionários da modernidade, até o século XVIII. ${ }^{13} \mathrm{O}$ compêndio de Plínio já utilizava a expressão para designar homens nascidos de pais de diferentes nações. O sentido, portanto, é o da origem grega e latina da palavra, ou seja, mistura, misto. Interessante é que Plinio parte, de acordo com Bluteau, do vocábulo Semiferus; semi-fera; o que nos dá a dimensão de uma percepção do outro, do que não é igual e se mistura com o identificado, com o próprio. Um sentido, enfim, de alteridade.

O dicionário de Bluteau, saliente-se, é o primeiro dicionário exclusivo da língua portuguesa. No verbete em análise ("Mestiço"), aponta-nos, para além de híbrido, a utilização de outras palavras com o mesmo sentido, quando cita as expressões latinas Bigenus, Bigenere e Bigeneris, no "Thesouro da Língua Latina" de Roberto Estêvão. ${ }^{14}$

\section{FRONTEIRAS DE CULTURA, CONTINUUNS CULTURAIS E HIBRIDISMO}

A ideia de continuum cultural, afirmando a inexistência de grupos identitários muito distintos e as fluidas fronteiras entre as culturas, tem desaguado no uso da expressão hibridismo cultural e em outras que buscam adjetivar as mesclas, as misturas e as trocas de experiências humanas. ${ }^{15}$ Hibridação (ou hibridização) e hibridismo têm reforço em seu uso, quando as reflexões direcionam-se para a discussão do chamado processo de globalização cultural intensificado pelos encontros culturais mais rápidos e mais frequentes, em regiões fronteiriças ou mais distantes, tão comuns em nosso tempo. ${ }^{16}$

É exemplar neste caso, e voltando a Peter Burke, a exemplificação de misturas ou de trocas em diversas áreas das manifestações culturais, da alimentação às práticas religiosas, dos costumes urbanos ao cinema, assim como nas línguas e na música. Diz o autor a certo momento: "Esse processo [globalização cultural] é particularmente óbvio no campo musical no caso de formas e gêneros híbridos como o jazz, o reggae, a salsa ou o rock afro-celta."17 "Gêneros híbridos" é, então, expressão através da qual o autor quer denotar, por exemplo, a riqueza do jazz por seus diálogos com os outros gêneros.

\footnotetext{
${ }^{13}$ Exemplo dessa literatura é O Non Plus Ultra do Lunário e Prognóstico Perpétuo Geral e Particular para todos os Reinos e Províncias, de Jerônimo Cortez, O Valenciano. Conhecido popularmente e muito citado por outros textos como O Lunário Perpétuo, este livro foi traduzido para o português por António da Silva de Brito e editado em Lisboa, em 1703, "emendado conforme o expurgatório da Santa Inquisição", como explicita a edição original na própria capa.

${ }^{14}$ Com relação ao termo mestizo, ele não aparece no dicionário de Espanhol-Latim de Antonio de Nebrija, datado de 1492, NEBRIJA (1495). Segundo Jack D. Forbes, "um novo conceito foi registrado por Hieronymo Cardoso no seu dicionário Português-Latim, preparado antes de 1569": “(Port.) Mestizo = (Lat.) Ibria, ae" (...) (Port.) mestiço, = Hybris, idis. Hibrida, ae. FORBES (1988, p. 100).

${ }^{15}$ BURKE (2003).

${ }^{16}$ Exemplo disso é o estudo de PIETERSE (1984, pp. 161-184).

${ }^{17}$ BURKE (2003, p. 15). Sublinhado nosso.
} 


\section{Hibridismo: \\ Um tropo enganoso e a história do uso de uma metáfora}

José Newton Coelho MENESES

Chegamos ao ponto, então, de nossa preocupação com a linguagem utilizada por nós para denotar o que queremos expressar. Temos usado, como antecipamos acima, adjetivos múltiplos para clarear uma dinâmica cultural complexa, produtora de repertórios ricos de manifestações e de formas de expressão e de vivências. Além de hibridismo, expressão alvo de minha preocupação neste texto, temos exemplos incontáveis de uso acadêmico-científico de expressões similares, mais ou menos tomadas e usadas para adjetivar o processo. A título de enumeração exemplar, podemos aqui mencionar algumas matrizes dessa busca instrumental no século XX, dentre outras: “mestiçagem”, usada por Gilberto Freyre em Casa Grande e Senzala, em 1933; “ajiaco" [“ensopado”], por Fernando Ortiz em Contrapunteo cubano, em 1940; “difração", metáfora que Arnold Toynbee utiliza em A Study of History, em 1953. ${ }^{18}$

Essas metáforas instrumentais para a denotação de uma caracterização de culturas tiveram ampla repercussão, umas mais, outras menos, umas de forma negativa, outras positivamente. No nosso tempo, mestiçagem é, talvez, uma de maior propagação dentre os estudos em línguas latinas.

$\mathrm{Na}$ sequência histórica das interpretações culturais, uma diversificada terminologia é criada na busca denotativa dos encontros, dos diálogos culturais e das misturas de culturas. Vejamos exemplos: imitação, apropriação, empréstimo, aculturação, assimilação, transculturação, transferência, troca, acomodação, diálogo, negociação, mistura, fusão, sincretismo, harmonização, polifonia, interpenetração, heterogeneidade, ..., todos eles substantivos que objetivam nomear processos culturais dinâmicos e ricos. ${ }^{19}$

Hibridação ou hibridismo adquire, nesse rol de palavras, uma hegemonia que busco entender e criticar. De historiadores da Antiguidade clássica a nós que buscamos interpretar os encontros de culturas no território do Novo Mundo, a tradução do fenômeno cultural e de seu repertório de manifestações, tem usado, talvez por influência da língua inglesa em sua hegemonia no ocidente, hibridização, hibridação, hibridismo e híbrido como metáforas instrumentais para denotar o encontro das culturas diversas, principalmente americanas, europeias e africanas, mas, também, indianas, e chinesas, árabes, judaicas etc, e a mescla de suas respectivas manifestações, também diversas e misturadas, no território das Américas colonizadas a partir da expansão europeia no mundo moderno. ${ }^{20}$

\footnotetext{
${ }^{18}$ FREYRE (1998); ORTIZ (1983); TOYNBEE (1987) [Resumo dos doze volumes da obra A Study of History do autor]. SAID (2003).

${ }^{19}$ Aqui, termos presentes em Gilberto Freyre, Fernando Ortiz, Roger Bastide, Mikhail Bakhtin, Edward Said, todos estudiosos que estão na matriz fundamental dos estudos culturais da atualidade. É interessante observar, que, também Gilberto Freyre utiliza a expressão híbrido/a como no título do Capítulo 1 de Casa Grande e Senzala, Características gerais da colonização portuguesa do Brasil: formação de uma sociedade agrária, escravocrata e híbrida. Sublinhado nosso.

${ }^{20}$ Perceptível a busca da historiografia sobre a Antiguidade de interpretar, por exemplo, o processo de helenização, não mais como a imitação ou a imposição da cultura grega, mas, diferentemente como se fazia pela tradição historiográfica, como uma dinâmica de interação entre culturas. A mesma perspectiva é verificada em estudos sobre processos de mudanças nas manifestações religiosas no período medieval e moderno, nos estudos sobre o Renascimento europeu e sobre as economias coloniais modernas.
} 
Ora, como no início deste texto, híbrido e hibridação, hibridização e hibridez, têm um histórico de utilização ampliado, mas que, a partir de Mendel, adquire, por força da "História Natural" e depois da Biologia, uma denotação de processo complexo, porém de ambiguidade em seus resultados práticos. A hibridação gera produção maior por um lado e anomalia, por outro; vigor e degenerescência; potência e infertilidade; possibilidades e incapacidades; opções reprodutivas e pobreza genética.

Ao contrário, a cultura que interpretamos, com diferenças claras nas correntes de pensamento, quer se demonstrar como produtiva, complexa, diversa, capaz, forte, dinâmica em sua reprodução, enfim, cultura rica. Não há, assim, universalidade no entendimento do hibridismo cultural ou da cultura híbrida, tendo a expressão um entendimento não consensual e, portanto, não possível de convencionar uma compreensão única, clara e denotativa, como almeja os parâmetros da linguagem que se quer acadêmica ou científica, em nosso tempo.

A metáfora do hibridismo, então, a partir de um entendimento botânico/zootécnico/racial, vai optando, em diferentes regiões e culturas por tropos referenciais (palavras de sentidos figurados) que tem em mestiçagem (no francês, no português, no espanhol e em italiano) uma amplitude espacial, mas em hibridismo, uma hegemonia no uso, pela falta de correspondência na língua inglesa de palavra correspondente à mestiçagem. O sentido que queremos dar, assim, toma uma expressão que não o denota, pela força de uma língua preponderante e hegemônica na comunicação entre as pessoas nos tempos atuais. Ao traduzir mestiçagem, hibridization tem a primazia de ser reproduzida em diversas línguas latinas, com o sentido que queremos dar à primeira expressão. Esse domínio linguístico constrói, então, novo sentido que, no entanto, não é consensual e, assim, perde força como convenção.

O uso moderno da metáfora em linguagem científica e na construção de conceitos é uma tentativa de ressaltar características, processos, bem como de sintetizar em uma palavra um conjunto de características definidas e convencionadas. Aí, o conceito tem de denotar e definir o objeto que se quer caracterizar de forma geral (nomear o que antes eram ideias). No caso aqui tratado, o conceito é buscado para definir os encontros culturais e sua dinâmica reprodutiva. Neste sentido, a palavra híbrido(a)/hibridismo é inconsistente e mestiço/mestiçagem é metáfora mais aderida à realidade do processo.

O presente texto, ressalto por fim, tem o objetivo de pensar criticamente os contornos semânticos da expressão híbrido/hibridismo em seus contextos histórico-sociais específicos. É necessário, ao final, ressaltar que há uma ética na construção da ideia e do conceito de mestiçagem cultural e nas representações identitárias dos encontros e diálogos culturais expressos por este conceito. ${ }^{21}$ Neste sentido também político, as expressões híbrido(a)/hibridismo, por sua dubiedade interpretativa, são pouco aderidas à uma realidade

\footnotetext{
${ }^{21}$ Ética, aqui, entendida como opção socialmente justificada de ação humana.
} 


\section{Hibridismo: \\ Um tropo enganoso e a história do uso de uma metáfora}

José Newton Coelho MENESES

que queremos interpretar e, assim, servem pouco como convenções para o entendimento denotativo de nossas interpretações.

A tradição, como transmissão no tempo, vem reconfigurando a ideia e os usos de hibridismo/híbrido, naturalizando sua compreensão como algo de complexidade rica. É preciso respeitar a tradição. Questioná-la, pode nos ser útil; mudá-la em certo tempo, pode ser necessário, salutar. O texto que aqui se encerra quis apenas problematizar, instigar reflexão. Vários tropos foram abandonados ou reiterados pelas mudanças que seus usos e significados sofrem no tempo. Hibridismo e híbrido têm história em seus usos metafóricos e é uma história rica. Por ser histórico, é um uso mutável. Não há na proposta reflexiva deste pequeno texto outra intenção que não seja a de questionar a repetição irrefletida de seu uso em nosso tempo.

\section{REFERÊNCIAS BIBLIOGRÁFICAS}

BURKE, Peter. Hibridismo cultural. São Leopoldo: Editora UNISINOS, 2003.

BLUTEAU, D. Raphael Bluteau. Vocabulario Portuguez e Latino Aulico, Anatomico, Architectonico, Bellico, Botanico, Brasilico, Comico, Crítico, Chimico, Dogmatico, Dialectico, Dendrologico, Ecclesiastico, Etymologico, Economico, Florifero, Forense, Fructifero, Geographico, Geometrico, Gnomonico, Hydrographico, Homonymico, Hierologico, Ichtyologico, Indico, Isagogico, Laconico, Liturgico, Lithologico, Medico, Musico, Meteorologico, Nautico, Numerico, Neoterico, Ortographico, Optico, Ornithologico, Poetico, Philologico, Pharmaceutico, Quidditativo, Qualitativo, Quantitutivo(sic), Rethorico, Rústico, Romano, Symbolico, Synonimico, Syllabico, Theologico, Terapteutico, Technologico, Uranologico, Xenophonico, Zoologico, autorizado com exemplos dos melhores escritores portugueses, e latinos; $e$ oferecido a el Rey de Portugal, D. João V, pelo Padre D. Raphael Bluteau clerigo regular, Doutor na Sagrada Theologia, Prêgador da Raynha de Inglaterra, Henriqueta Maria de França, \& Calificador no sagrado Tribunal da Inquisição de Lisboa. Coimbra: Collegio das Artes da Companhia de Jesus, 1712.

CHEVALIER, Jean \& GHEERBRANT, Alain. Dicionário de Símbolos. $20^{\mathrm{a}}$ edição. Rio de Janeiro: José Olympio Editora, 2006.

DIWAN, Pietra. Raça pura; uma história da eugenia no Brasil e no mundo. São Paulo: Contexto, 2007.

FERREIRA, Aurélio Buarque de Holanda. Dicionário Básico da Língua Portuguesa. Rio de Janeiro: Nova Fronteira, 1988.

FORBES, Jack D Forbes. Black Africans \& Native Americans. Color, Race and Caste in the Evolution of Red-Black Peoples. Oxford: Basil Blackwell Ltd., 1988.

FREYRE, Gilberto. Casa Grande e Senzala. 34 ${ }^{\mathrm{a}}$ Ed. Rio de Janeiro: Record, 1998.

HOUAIS, Antônio. Dicionário Houais. Rio de Janeiro: Objetiva, 2003.

MURAKAWA, Clotilde de Almeida Azevedo. António de Morais Silva: Lexicógrafo da Língua Portuguesa. Araraquara: Editora Cultura Acadêmica, 2006. 
MURAKAWA, Clotilde de Almeida Azevedo. Os dicionários de Bluteau, Morais e Vieira e sua importância na história da lexicografia portuguesa. Actas do Encontro da Associação Portuguesa de Lingüística, v. II, pp. 495-503, 1997.

NEBRIJA, Elio Antonio de. Vocabulario español-latino. Salamanca, 1495.

NUNES, José Horta. Bibliografia de Dicionários da Língua Portuguesa. Portal Conhecendo Dicionários (CDIC), Universidade Estadual Paulista (Unesp), sem data.

ORTIZ, Fernando. Contrapunteo cubano del azúcar y del tabaco. Havana: Editorial de Ciencias Sociales, 1983.

PETTER, Margarida Petter \& NUNES, José Horta (Orgs.). História do saber lexical e constituição de um léxico brasileiro. São Paulo: Humanitas; Campinas: Pontes, 2002.

PIETERSE, Jan Nederveen. Globalization as Hybridization. International Sociology 9, pp. 161-184, 1984.

SAID, Edward W. Orientalismo: o Oriente como invenção do Ocidente. São Paulo: Companhia das Letras, 2003.

SILVA, Antonio de Moraes. Diccionario da lingua portugueza - recopilado dos vocabularios impressos ate agora, e nesta segunda edição novamente emendado e muito acrescentado, por Antonio de Moraes Silva. Lisboa: Typographia Lacerdina, 1813.

SILVESTRE, João Paulo. Bluteau e as Origens da Lexicografia Moderna. Brasília: Imprensa Nacional/ Casa da Moeda, 2009.

TOYNBEE, Arnold. Um estudo da História. São Paulo: Martins Fontes, 1987.

VERDELHO, Telmo. Dicionários portugueses, breve história. Publicações do Corpus Lexicográfico do Português. Aveiro: Universidade de Aveiro, in: http://clp.dlc.ua.pt/Publicacoes/Dicionarios, sem data.

VERDELHO, Telmo. O dicionário de Morais Silva e o início da lexicografia moderna. História da língua e história da gramática - Actas do encontro. Braga: Universidade do Minho. ILC, pp.474-490, 2003. in: http://clp.dlc.ua.pt/Publicacoes/Dicionarios_Morais_Silva.pdf

Texto recebido em: 30/03/2020

Texto aprovado em: 30/04/2020 